\title{
"Smart Stall" Artificial Intelligence Solution -Vendor Economy and Its Transformation Model from the Perspective of Artificial Intelligence
}

\author{
Lingqing Liu $^{1 *}$, Jing $\mathrm{Lu}^{2}$, a, Minyu Huang ${ }^{2, \mathrm{~b}}$ \\ ${ }^{1}$ Sichuan University, Computer Science and Technology, School of Computer Science. Financial Engineering, School \\ of Economics \\ ${ }^{2}$ TIANIIN NORMAL UNIVERSITY, Chinese and foreign political systems, College of Politics and Public \\ Administration \\ ${ }^{2}$ Beijing University of Chemical Technology, International Economics and Trade, School of Economics and \\ Management \\ *lingqing_liu@foxmail.com \\ atjnulu@126.com \\ b13278822100@163.com
}

\begin{abstract}
With the sweeping of COVID-19, the domestic and foreign economies show a downward trend. As one of the main forces of the national economy, vendor economy shoulders the important task of alleviating economic pressure and promoting employment. In recent years, with the rapid development of artificial intelligence, it has gone out of the laboratory and entered people's life. This article aims to study the integration of AI and vendor economy under the situation of COVID-19, and discuss the new trend of 3.0 Transformation of vendor economy. The so-called artificial intelligence refers to the technology of presenting human intelligence through ordinary computer programs. Whether it is machine learning, data mining or computer vision, it is mainly involved in the research field. Thus, the two rapidly developing industries collide with each other, contributing to the rapid, convenient and orderly development of residents' lives under the epidemic situation. This article starts from 1.0 of vendor economy under the background of epidemic situation, and describes in detail the application of various technologies of artificial intelligence in the direction of "smart stall". The vendor economy has developed from 1.0 to 2.0, and even move towards 3.0 with the development of $\mathrm{AI}$ in the future.
\end{abstract}

Keywords: Artificial Intelligence, Vendor economy, Transformation, Development trend

\section{BACKGROUND AND POLICY}

\subsection{Introduction}

Street vendors are an integral part of urban economies around the world, offering easy access to a wide range of goods and services in public spaces. The development of "street vendor economy", on the one hand, solves the problem of consumers' lack of confidence in indoor consumption in restaurants, stores and other stores under the epidemic prevention and control, and also greatly meets the current epidemic prevention and control requirements. There is no transfer fee, no decoration fee, no pressure on store rent, no pressure on employees' wages, and no need to pay taxes. This not only reduces the operating costs of merchants, but also enhances the vitality of consumer market entities. On the other hand, people who lost their jobs due to the epidemic have realized flexible employment by setting up stalls. Under the situation of COVID-19, the vendor economy will achieve sustainable development with the promotion of AI. And the future, AI will help the local economy to enter the 3.0 era, which will be more convenient, efficient and better able to serve people's livelihood. 


\subsection{The impact of the epidemic on the street vendor economy}

\subsubsection{In China}

In 2020, the national economy was hit hard by the COVID-19 pandemic, and the number of unemployed people soared. Therefore, various provinces and cities have issued a series of policies to promote the opening-up of the street economy, in order to provide support for the resumption of work and production in China. For example, Chengdu city of Sichuan Province released the Action Plan of Chengdu City to Boost Domestic Demand by Taking New Consumption as the Lead (2020-2022) to support the streets with conditions to carry out a pilot program of external locations at specific periods at night, so as to form a nighttime economic ecosystem and improve nighttime economic vitality.

\section{DISTRIBUTION LAW OF STALL SITES IN CHINA}

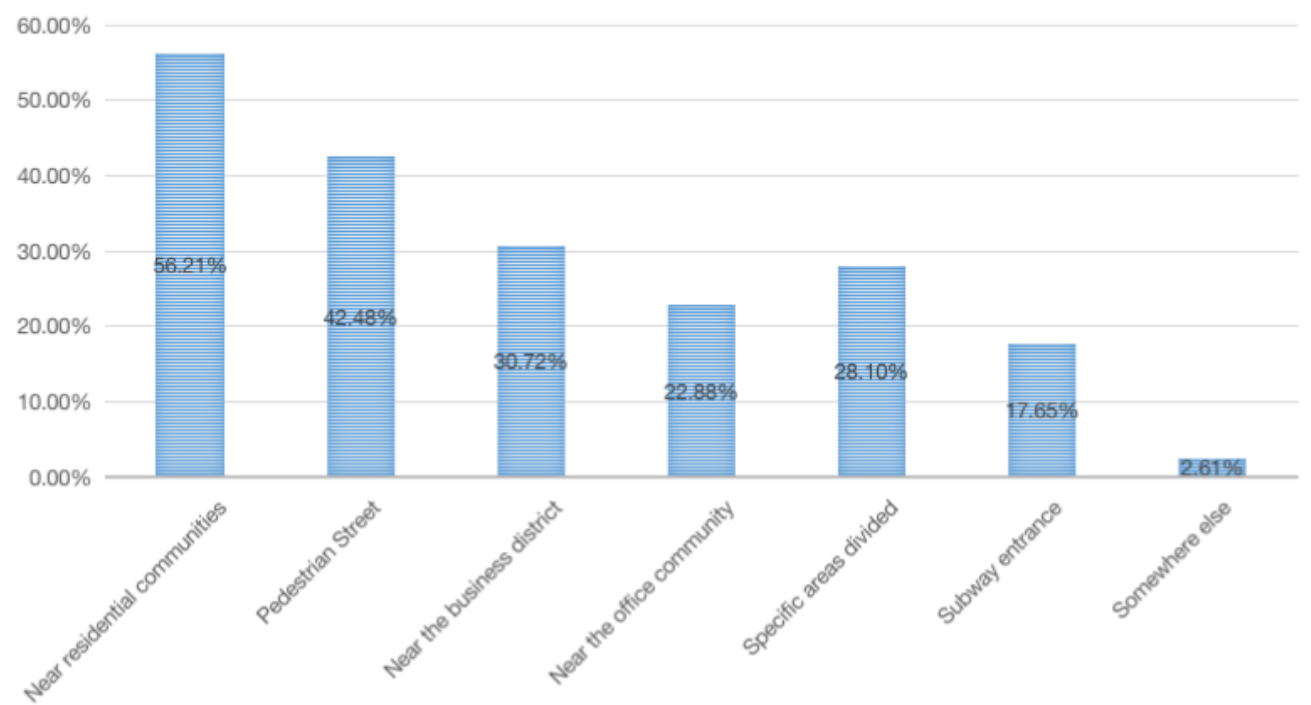

Figure 1: Distribution law of stall sites in China

\subsubsection{In Latin America}

By the end of 2020, Latin America's cumulative COVID-19 caseload accounted for more than a fifth of the known global tally, despite the region accounting for under a tenth of the world's population.[1] And governments across the region closed their countries' borders and started enacting and implementing regulations to give effect to a full or partial lockdown of the population. Many of the laws and regulations in response to COVID-19 had a deeply negative impact on informal vendors, who make up a significant portion of Latin American countries' economically active population, as Figure 1 shows, while there income depends on access to public space and social interaction.

The challenge for Governments at national and local levels in Latin America is, how to recover and manage the vendor economy after COVID-19. It entails adopting legislation that enhances the "livelihoods, working conditions and income security, legal and social protection, access to skills and other support services" [2] of informal vendors. Besides, it would also be a good way to introduce artificial intelligence to help manage and develop street vendors, the vendor economy will be driven by artificial intelligence to achieve unexpected development. 


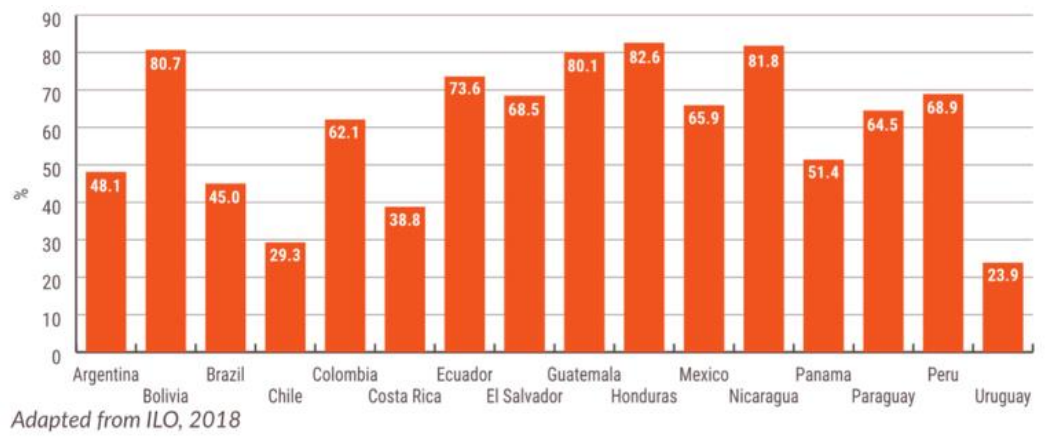

Figure 2: Informal workers as a percentage of the economically active population (https://www.wiego.org/publications/impact-covid-19-laws-street-vendors-and-market-traders-trends-and-insights-lati n)

\section{THE TRANSFORMATION OF BOOTH ECONOMY FROM 1.0 TO 3.0}

As the starting and ending point of economic activities, payment plays an indispensable role in the complete operation of the national economy. The integration of Internet technology and payment methods has opened up a whole new payment field, redefined the whole payment system, and reflected great economic value in promoting economic reform and development, regulation and improvement of the market economy.[3] Here we explore the relevance of payment system innovation and the development of the ground-floor economy by the stage evolution of payment methods 1.0, 2.0 and 3.0.

\subsection{Development details}

The stall 1.0 era is the most traditional one. We can find both gold and copper coins in the Qin and Han dynasties, copper coins and silver ingots in the Ming and Qing dynasties, and later food stamps. The era of general equivalence after bartering tends to be the longest.

The platform of the booth 2.0 era is marked by the promotion of technological means represented by electronic payment and Internet finance. Traditional means of finance, payment and regulation are rapidly developing and evolving new innovative models driven by Internet technology, which in turn brings new opportunities and requirements for transactions and regulation of the vendor economy. Based on the measurement results of the former Planning Commission's Science and Technology Department group, a comparative study found that the contribution rate of scientific and technological progress to economic growth from 1979-2015 was much higher than the degree of contribution of capital and labor factors. The average annual progress rate of science and technology is $5 \%$ and the contribution rate is $47 \%$.[4] Thus, a correct understanding of scientific development is particularly important to promote the development of the vendor economy. At the same time, the ground vendor economy has the characteristics of small cost, mobility, simplicity and speed, which puts forward new demands for simplifying the transaction process and improving circulation efficiency. While we innovate to promote the economic development of the stalls, we are also providing technological wisdom for the promotion of technological undertakings.

The 3.0 era of stalls is the new era of artificial intelligence innovation in the $21 \mathrm{st}$ century, and the innovative development of the vendor economy and technological progress are complementary to each other. The demand for technological advancement in the standardized management of the vendor economy is reflected in the high-definition surveillance and capture of occupied stalls, intelligent security, intelligent light poles, intelligent video analysis systems, and intelligent urban management technologies, which are characterized by "panoramic open-viewism" control of space.[5] We find that the vendor economy is gradually formalizing and promoting the development of artificial intelligence. The economic applications of artificial intelligence continue to innovate and develop on the basis of algorithms, statistics, data, and networks. "Decentralized" technological advances, such as blockchain, are also important in facilitating the development of the vendor economy. Artificial intelligence can support high-yield, high-quality business activities, as well as basic trading models such as the booth economy. By simulating different scenarios, we can create more social value for the vendor economy. 


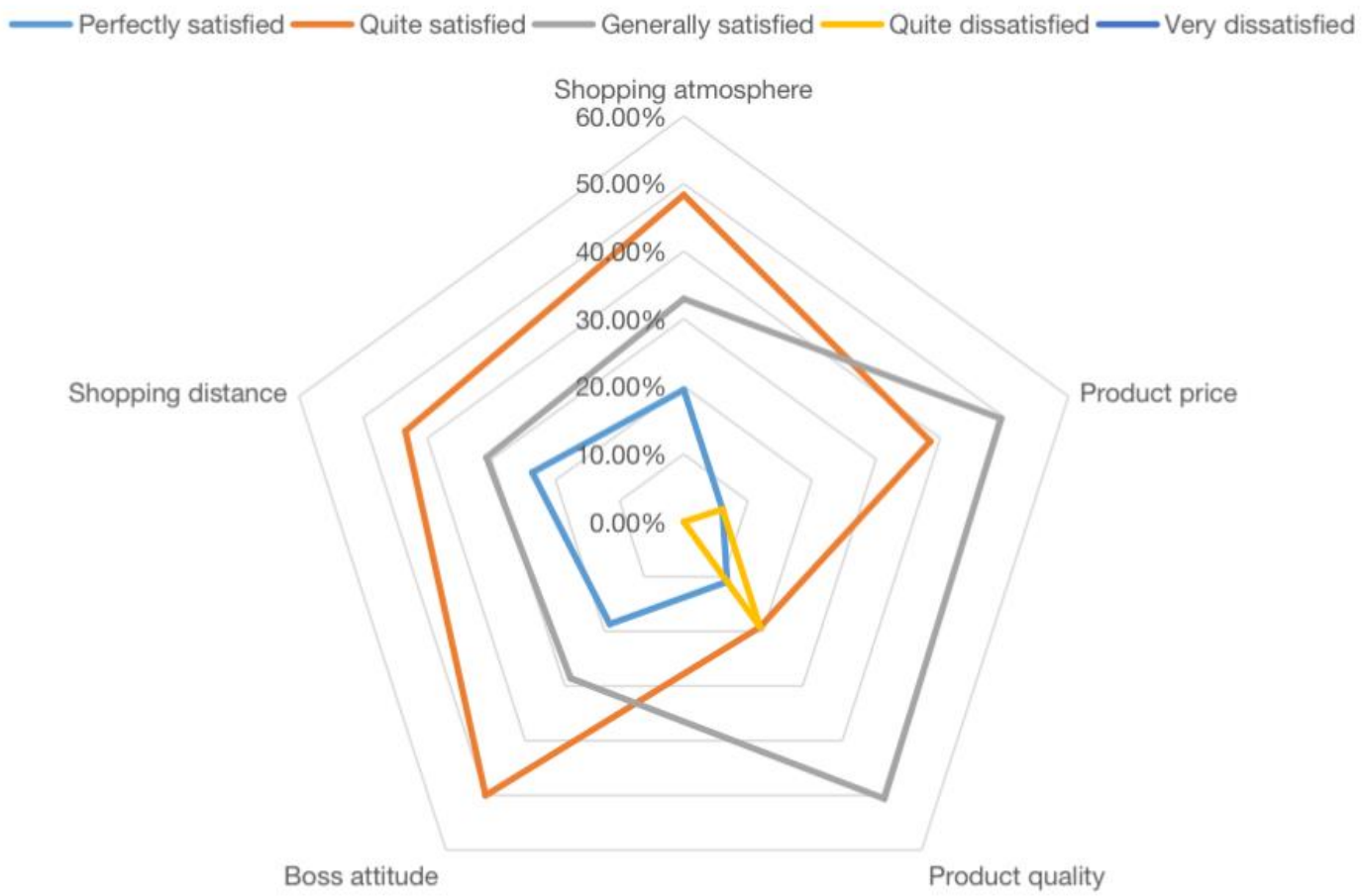

Figure 3: Overall satisfaction distribution of Chinese respondents' stall consumption in the first half of 2020

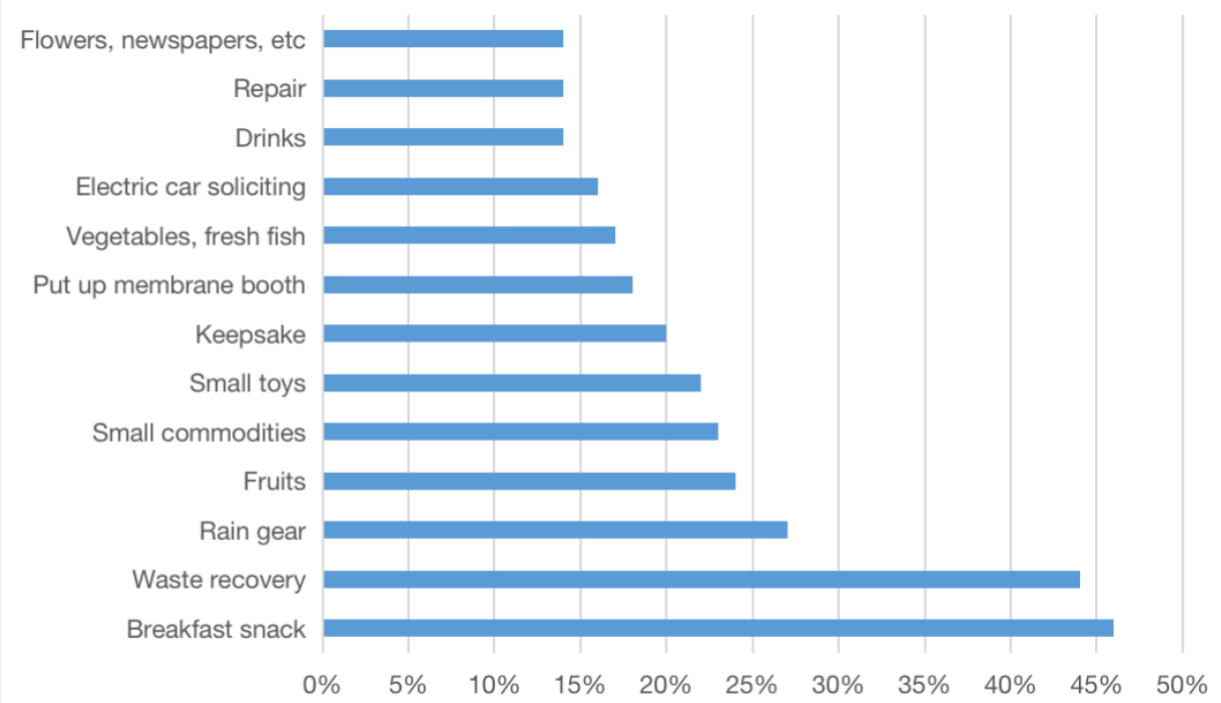

Figure 4: Economic operation types of stall

\subsection{Stall 3.0 transformation}

In the past ten years, the market share economy has made irreplaceable contributions to solving the employment rate problem, driving the development of rural cities and towns, and fighting poverty. The country regards the vendor economy as part of the assessment of the national civilized cities. It is this basic business model that meets the basic needs of the city. We also realize that driving the stall 3.0 should be developed under the prerequisites for building civilization. Due to its low operating costs, the market share economy requires low levels of culture and education for sellers, and because of the randomness of the transaction location of the market economy, it can efficiently and quickly promote the circulation of funds to reduce the margin caused by excessive accumulation of goods in the post-epidemic era. The impact of the effect, because different raw materials sold in different stalls can generate different demand, and then generate revenue. In the era of stall 3.0, we pay more attention to the transformational development of vendor economy from informality to formality; the development of community outside the community, through the community as the center point, the formation of stalls covering the city, individuals promote the overall model, fundamentally 
promote The development of artificial intelligence; the development of commerciality to public welfare, starting from the transformation of the payment method of the market economy, and promoting the innovation of artificial intelligence in new fields.

By studying the existing artificial intelligence applications, we make the following prospects that can be realized in the future:

First, the vendor economy will achieve sustainable development under the impetus of artificial intelligence. As a cognitive science in the new era, artificial intelligence is constantly exploring the process of human behavior simulation on the way of innovation, and constantly innovating in theory during its development. At the same time, it also generates continuous demand in practice. It is an important and important condition for promoting the development of the vendor economy. We are well aware that the prospects for the development of artificial intelligence are broad, and there are still many gaps in the practical results that can be applied to the vendor economy, and there are still many that are worth exploring in the process of achieving sustainable development.

Second, artificial intelligence will continue to provide a proactive monetary policy. The inevitability of the industrial upgrade of the vendor economy is self-evident. Naturally, more people will join the industry. Because of the low cost of the vendor economy, people continue to borrow from banks. While the development of artificial intelligence, it is also advancing the continuous development of marketization.

Third, artificial intelligence will drive the transformation and development of the vendor economy. The current economic development situation obviously cannot meet the needs of future development. In today's rapid social development, consumption is the core of increasing residents' income. Export and investment are the ways to improve the level of consumption. Continuously increasing the level of consumption is the first priority to promote economic development. High-definition surveillance captures occupying road stalls, smart security, smart light poles, video intelligent analysis systems, and smart city management systems are the economic applications of existing artificial intelligence stalls. Based on existing applications, we propose a platform-based management model for food safety AI supervision, fresh food supply chain, electronic fence + positioning, opening reminders and management data supervision, and smart cars for stalls. These ideas will be described detailly in the next part.

Table 1: Main benefit areas under the background of stall economy

\begin{tabular}{|c|c|c|}
\hline The name of company & Revenue direction & Industry \\
\hline TSINGTAO BEER & \multirow{3}{*}{$\begin{array}{l}\text { Beer: stall economy promotes the } \\
\text { development of snack catering. Most beer } \\
\text { scenes are public catering }\end{array}$} & Food and beverage \\
\hline CRB & & Food and beverage \\
\hline Pearl Rivetr Beer & & Food and beverage \\
\hline Anji food & \multirow{2}{*}{$\begin{array}{l}\text { Quick frozen food: catering products are } \\
\text { sold to Malatang barbecue shop }\end{array}$} & Food and beverage \\
\hline Sanquan foods & & Food and beverage \\
\hline Seasonable food & $\begin{array}{c}\text { Condiment: } 2 \mathrm{~B} \text { channel accounts for a large } \\
\text { proportion }\end{array}$ & Food and beverage \\
\hline Master Kang & \multirow{2}{*}{$\begin{array}{c}\text { Beverages: night snack stalls and Malatang } \\
\text { barbecue shops prefer beverages, especially } \\
\text { carbonated drinks. }\end{array}$} & Food and beverage \\
\hline Chinese food & & Food and beverage \\
\hline Jue Wei & \multirow{2}{*}{$\begin{array}{l}\text { Leisure brine products: the flow of people } \\
\text { going out increases, and the consumer } \\
\text { demand for duck neck, string and so on } \\
\text { increases }\end{array}$} & Food and beverage \\
\hline Zhou Hei Ya & & Food and beverage \\
\hline Jin Fa technology & \multirow{3}{*}{$\begin{array}{l}\text { Daily chemical supplies and raw materials } \\
\text { related to stall operation }\end{array}$} & Material Science \\
\hline Wanhua chemical & & Material Science \\
\hline Yingfeng environment & & Utilities \\
\hline Feike electric appliance & $\begin{array}{c}\text { Small household appliances related to stall } \\
\text { operation }\end{array}$ & Durable consumer goods \\
\hline China Gas & Canned liquefied gas & Energy \\
\hline Changan Automobile & \multirow{2}{*}{$\begin{array}{c}\text { Special vehicles and two wheeled vehicles } \\
\text { for stall operation }\end{array}$} & Automobile \\
\hline Tianneng force & & Automobile \\
\hline Yunda & \multirow{2}{*}{ Logistics } & Transmit \\
\hline Zhongtong & & Transmit \\
\hline
\end{tabular}




\section{THE APPLICATION OF ARTIFICIAL INTELLIGENCE IN HELPING STREET VENDOR}

\subsection{Existing application forms of artificial intelligence to help the development of vendor economy}

\subsubsection{High-definition video}

For a long time, "road occupation management" has always been one of the topics criticized by people. Due to the problems of traffic congestion caused by random road occupation, littering affecting the city appearance, non-standard business hours and disturbing residents at night, the stall was regarded as the "first culprit" of "dirty, messy and poor" in the city. However, today, the "black technology" management represented by artificial intelligence technology has become the label of China's modernization.

In the past, many illegal vendors used to occupy roads and set up stalls to sell agricultural products every day, resulting in serious traffic congestion in the urban area. The traffic police use high-definition probes to cooperate with law enforcement and capture random stops. It has achieved remarkable results in capturing and occupying the road and setting up stalls. On the electronic map, the situation of each monitoring point can be played in real time. For road stalls, even urban traffic and theft will be monitored. As long as the police receive a complaint, they can handle it and obtain evidence in time.

More than 20 cities are also equipped with more advanced system equipment. For example, the use of the sixth generation high-level video intelligent parking management system, which adopts artificial intelligence visual recognition technology and Internet of things technology, makes the temporary road occupation effectively managed with advanced technology. In the Internet of things environment, just remotely upgrade the front-end host identification algorithm distributed in different cities through the Elite LOTTOP data collection and distribution stack, so as to accurately identify the stalls that are not placed within the specified range and time. At the same time, the violation information is transmitted to the mobile phone of law enforcement personnel in real time through the operation management platform. After receiving the information reminder, law enforcement officers can quickly rush to the scene for persuasion or punishment [6].

In addition, the high-definition pedestrian flow detection camera can monitor the pedestrian flow in real time and inform the urban management personnel through the system. Managers can also view the thermal map of pedestrian flow distribution through the system to accurately locate the trajectory of each pedestrian, timely dredge the pedestrian flow and ensure safety.

\subsubsection{Wisdom lamp post}

Wisdom lamp post can not only provide omnidirectional real-time video monitoring, but also a walking WIFI transmitter and charging treasure. It integrates WIFI wireless network, video monitoring, environmental monitoring, emergency broadcasting, advertising screen and other functional modules, and forms a data-based information system.

In addition, it also undertakes the tasks of monitoring, video and broadcast notification. This allows city managers to monitor stall setting and issue management notices through the system at any time. Last but not least, it can also automatically adjust the brightness according to the ambient light and human flow. There is no doubt that wisdom lamp post not only improves management efficiency, but also helps to save energy and reduce emissions [7].

\subsubsection{Video intelligent analysis system}

Usually, the video intelligent analysis system can automatically capture and report more than 50 violations, including road occupation operation and road waterlogging. Using new technologies such as big data and artificial intelligence, it can automatically capture and automatically identify the specific situation of urban management problems, and automatically generate relevant information such as location, problem description and street community.

At the same time, it can also realize one key approval, automatic dispatch, intelligent verification, intelligent case closing and data analysis. The high incidence types and regions of cases on that day can be automatically analyzed and scrolled on the screen in real time for relevant personnel to refer to and make decisions.

\subsubsection{Wisdom city management}

The trend of government and smart city has further converged to jointly shape the smart urban management. It is supported by a new generation of information technology represented by the Internet of things and cloud computing. At first, through comprehensive and thorough perception, broadband ubiquitous interconnection and intelligent integration application, taking citizens as the center and urban society as the stage, we can realize the public value shaping and unique value creation of urban managers, market and society, and realize the transformation of urban management from production paradigm to service paradigm. 


\subsubsection{Intelligent security}

To achieve intelligent security, digital intelligent urban management video monitoring system also plays an important role. Under the vendor economy, the large-scale application of monitoring, storage and network equipment can realize the online monitoring of municipal administration and city appearance within the city. It provides strong support for the urban management department to quickly find violations and track the progress of event handling in real time. It can also greatly improve the standardization of stall market operation and enhance the harmonious city image.

Food street, night market and other places have dense stalls, common open fires and high risk of power consumption. It is a matter of great concern for managers to detect risks in time and ensure the completeness of fire-fighting facilities. Locate, monitor and give early warning to all fire prone equipment and gas equipment in catering area. The intelligent electrical fire monitoring system works 24 hours a day. Once the electrical hazard is detected, it will automatically power off and remind the manager to strangle the electrical fire in the cradle. The operation status of fire-fighting facilities is also under 24-hour monitoring. In case of fire hydrant damage, insufficient fire water pressure, well cover offset and other problems, the manager can receive the alarm at the first time through the system to ensure that the fire-fighting facilities are "ready at all times".

\subsection{The main form of vendor economy 3.0 in the future}

Even though artificial intelligence has gradually begun to empower the vendor economy, the combination of vendor economy and artificial intelligence has not reached a complete transformation. Artificial intelligence will create more possibilities with the development of vendor economy in the future. There is still much room for the development of artificial intelligence in terms of production efficiency, safety guarantee, coverage supervision, sanitation and cleaning under the vendor economy. Facing some existing difficulties, artificial intelligence is expected to escort it [8].

Table 2: Layout of Smart Stall

\begin{tabular}{c|c}
\hline Intelligent stall solution Division & Related technology \\
\hline Intelligent stall management solution & Big data, Internet of things technology, machine learning \\
\hline Intelligent garbage system & Machine learning, computer vision, robotics \\
\hline Intelligent ground truck solution & Machine learning, computer vision, robotics, \\
\hline Intelligent stall ordering solution & Internet of things technolohy \\
\hline Smart stall power sharing solution & Internet of things technology, machine learning, deep learning \\
\hline Intelligent Stall lighting solution & Big data, computer cision \\
\hline Shared stall solution & Big data, Internet of things technology, machine learning, computer \\
vision, deep learning
\end{tabular}

\subsubsection{Electronic fence + positioning}

Electronic fence + positioning is another solution to the possible behaviors of stalls such as road occupation, environmental pollution and noise pollution. Based on the existing high-definition camera, it carries out urban management in a more advanced way.

If the exclusive land for the stall is given in the urban planning, the intelligent supervision may be carried out through electronic fence + vehicle positioning. At the same time, by giving the stall exclusive area, it can not only promote the establishment of night market culture full of human smoke and fire, but also trace back to the health director of each part. Once it is traced back to the person in charge of health in real time, the noise and environmental impact on residents can be reduced in time.

\subsubsection{Stall SaaS platform}

SaaS platform is a wide range of coverage and supervision of land stalls. With the development of big data and artificial intelligence, technology has been able to empower the local economy, enabling it to realize digital operation, bringing great changes in supervision and operation.

Based on SaaS platform, the government can access the business data of each stall store through app. On the one hand, it can achieve effective supervision in tax and other aspects. On the other hand, it can also realize the 
popularity ranking of stall stores based on big data, so as to make excellent stores more widely known. More importantly, this can help those stall shops that are good at cooking but ignore marketing no longer suffer losses, letting the diet return to taste and reputation.

\subsubsection{Upgraded intelligent stall truck}

After SGMW put forward the slogan of "night market 2.0 must be driven by science and technology", the high-tech barbecue stall truck enabled by artificial intelligence technology came into being. It is not difficult to see that there is a huge demand for floor stalls in the market.

However, this wing opening van only makes some simple modifications to traditional vehicles. It is far from enough for the hot offline scene of vendor economy. If the automation of some cumbersome details can be realized, the productivity of stall owners will be greatly improved.

In addition, energy is also a key consumption for the ground truck traveling outside. Although there are gas, battery and other resources, there are still deficiencies in safety and convenience. For the panels that need to face the sun for a long time, if solar energy and other resources can be stored and utilized, it will undoubtedly greatly simplify some processes and make the vendor economy greener.

\subsubsection{Food quality inspection}

Many people still have doubts about the items in the stall, which inevitably leads to the initial feeling of "dirty, messy and poor". In particular, food and other issues related to people's health are intolerable. Then, with the development of blockchain and other technologies, food materials can be truly traceable to truly track problems and realize the transparency of food production process.

In addition, artificial intelligence technology can also detect the quality of food materials, so as to greatly reduce the possibility of unscrupulous businessmen. The participation of artificial intelligence helps and ensures people's health and safety, making people more assured.

\section{CONCLUSION}

Under the situation of COVID-19, the vendor economy will achieve sustainable development with the promotion of AI. The development prospect of artificial intelligence is very broad. There are still many gaps in the integration practice with vendor economy. At the same time, AI will continue to provide active monetary policy. With the help of artificial intelligence and other technologies, vendor economy is not just a short-term emergence. In the near future, the vendor economy can also become a new growth point to really stimulate employment and serve the people's livelihood.

\section{REFERENCES}

[1] United Nations Office for the Coordination of Humanitarian Affairs. 2020. OCHA annual report 2020. United Nations, New York, NY.

[2] United Nations. 2017. World population prospects: The 2017 revision. United Nations, New York, NY.

[3] Xiao Ming Zhang. 2015. Research on the operation mode and development strategy of Internet finance. $\mathrm{PhD}$ Thesis, Shanxi University of Finance and Economics.

[4] D. Q. Tan. 2000. Improvement to the C-D production function for measuring the contribution rate of scientific and technological progress. Songliao J., 2, 61-62.

[5] S. L. Li and H. Pang. 2000. Spatial disciplineUnderstanding the key concept of Michel Foucault's spatial theory. Chinese Foreign Cult. Lit., 1.

[6] Elite LOTTOP. 2020. From concentrating on "intelligent governance" to specializing in many abilities, intelligently manage the stall. Sohu News.

[7] Shunzhou Intelligence. 2020. "Smart stall” Internet of things solution: let the world have no difficult stalls. Sohu News.

[8] Qiang Ye Ma, Zhao Hui Huang, Zi Yi Zhang, and Wei Xiao. 2021. Artificial intelligence helps the high-quality development of "stall economy." Chinese Mark., 20, 3. 